\title{
Durability of Photocatalytic Cement after Nitric Oxide-Wet-Dry Cycling
}

\author{
Lee, Bo Yeon ${ }^{1 *}$ \\ Kurtis, Kimberly E. ${ }^{2}$ \\ Department of Architectural Engineering, The University of Suwon, Hwaseong-si, Gyeonggi-do, 445-743, Korea ${ }^{1}$ \\ Civil and Environmental Engineering, Georgia Institute of Technology, 770 Atlantic Dr. Atlanta, GA 30332-0355, USA ${ }^{2}$
}

\section{Abstract}

Photocatalytic cement has been receiving attention due to its high oxidation power that reduces nitrogen oxide, thus contributing to a clean atmospheric environment. However, there has not yet been a thorough investigation on the effect of photocatalytic reactions on the durability of cementitious material, the parent material. In this study, photocatalytic cement samples were exposed to nitric oxide gas and UV along with cycles of wetting and drying to simulate environmental conditions. The surface of samples was characterized mechanically, chemically, and visually during the cycling. The results indicate that that the photocatalytic efficiency decreased with continued NO oxidation. The pits found from SEM indicated that chemical deterioration, such as acid attack or leaching, did occur. However, this was not confirmed by $\mathrm{X}$-ray diffraction. The hardness was not affected, probably due to the formation of CSH as evidenced by the XRD pattern. In conclusion, it was found that photocatalysis could alter cementitious materials both chemically and mechanically, which could further affect long-term durability.

Keywords : photocatalytic oxidation, deterioration, titanium dioxide, nitric oxide

\section{Introduction}

Photocatalytic cement containing nano-sized titanium dioxide $\left(\mathrm{TiO}_{2}\right)$ is known to effectively oxidize nitrogen oxides (NOx), one of the major air pollutants, improving air quality[1,2,3,4,5]. It is widely believed that the oxidation products of $\mathrm{NOx}$ (nitric oxide (NO) and nitrogen dioxide $\left(\mathrm{NO}_{2}\right)$ ) are nitrate ion $\left(\mathrm{NO}_{3}^{-}\right)$and nitrite ion $\left(\mathrm{NO}_{2}^{-}\right)$, or when dissolved in water, nitric acid $\left(\mathrm{HNO}_{3}\right)$ and nitrous acid $\left(\mathrm{HNO}_{2}\right)[6,7,8,9,10,11]$. Although many researchers have proposed mechanisms for the NOx oxidation reaction on $\mathrm{TiO}_{2}$ particles, the detailed mechanism is still not fully established. However, the set of chemical reactions proposed by Ndour gives us a

\section{Received : January 23, 2014}

Revision received : March 25, 2014

Accepted : April 25, 2014

* Corresponding author: Lee, Bo Yeon

[Tel: 82-31-229-8170, E-mail: bylee@suwon.ac.kr]

(c)2014 The Korea Institute of Building Construction, All rights reserved. general understanding of the mechanism. Equation (1) shows the NOx oxidation mechanism proposed by Ndour[11]. When a photon that has higher energy than the band gap energy of $\mathrm{TiO}_{2}$ is in direct contact with the $\mathrm{TiO}_{2}$, an electron $\left(\mathrm{e}^{-}\right)$is excited from the valence band (VB) to the conduction band (CB), leaving a hole $\left(\mathrm{h}^{+}\right)$behind. This energy-rich electron-hole pair $\left(\mathrm{e}^{-}-\mathrm{h}^{+}\right)$takes part in photocatalytic oxidation and reduction reactions. The band gap energy of $\mathrm{TiO}_{2}$ corresponds to an absorption threshold of $384 \mathrm{~nm}$ wavelength, which is near UV light range $(360-380 \mathrm{~nm})$. As the UV light is irradiated, reduction occurs at the $\mathrm{CB}$ and oxidation occurs at the VB. During this chain of chemical reactions, highly reactive superoxide radical-anions $\left(\mathrm{O}_{2}^{-}\right)$and hydroxyl radicals $(\cdot \mathrm{OH})$ are expected to form on the surface of $\mathrm{TiO}_{2}$ nanoparticles, which then decompose organic and inorganic pollutants as well as micro-organisms adsorbed on the surface. 
On valence band, $\mathrm{h}^{+}+\mathrm{H}_{2} \mathrm{O} \rightarrow \cdot \mathrm{OH}+\mathrm{H}^{+}--(1)$

$$
\mathrm{NO}_{2}+\cdot \mathrm{OH} \rightarrow \mathrm{HNO}_{3}
$$

On conduction band, $\mathrm{e}^{-+} \mathrm{O}_{2} \rightarrow \mathrm{O}_{2}^{-}$

$$
\mathrm{NO}_{2}+\mathrm{O}_{2}^{-}+\mathrm{H}^{+} \rightarrow \mathrm{HNO}_{2}+\mathrm{O}_{2}
$$

Leading to the following postulated catalytic net reaction:

$$
2 \mathrm{NO}_{2}+\mathrm{H}_{2} \mathrm{O} \stackrel{+\mathrm{hv}, \mathrm{TiO}_{2}}{\longrightarrow} \mathrm{HNO}_{2}+\mathrm{HNO}_{3}
$$

These reaction products, $\mathrm{HNO}_{2}$ and $\mathrm{HNO}_{3}$, are known to accumulate on the surface of a material, decreasing the photocatalytic efficiency. The reaction can be recovered when nitric acid is washed away by rain, which is further promoted by the hydrophilic property of $\mathrm{TiO}_{2}$.

However, there has not been much research regarding the effect of the product of the oxidation reaction (nitrates and nitrites) on cementitious materials. Since cement-based materials undergo various chemical reactions throughout their lifetime, the introduction of new ions might adversely affect existing cement components. For example, nitric acid, which is a strong acid, is detrimental to the cementitious substrate, which is stable at high alkalinity ( $\mathrm{pH}$ 12.5-13.5) and contains mineral phases subject to decomposition at lower $\mathrm{pH}$. When hydrated cement based material is subjected to aggressive acidic solutions containing anions such as nitric acid, the alkalinity of the pore solution decreases. The decrease in $\mathrm{pH}$ then brings the surface of cement to a state of chemical disequilibrium, eventually destabilizing the hydration products of cement. Calcium hydroxide $\left(\mathrm{Ca}(\mathrm{OH})_{2}\right.$ or $\left.\mathrm{CH}\right)$ decomposes as the $\mathrm{pH}$ drops below 12.5, ettringite decomposes at $\mathrm{pH}$ below 11, and calcium silicate hydrate $(\mathrm{C}-\mathrm{S}-\mathrm{H})$ decalcifies as the $\mathrm{pH}$ decreases, and decomposes at $\mathrm{pH}$ values below 9. Most pronounced of all is the decomposition of $\mathrm{CH}$; the chemical representation of this reaction under nitric acid attack is shown in equation (2).

$$
2 \mathrm{HNO}_{3}+\mathrm{Ca}(\mathrm{OH})_{2} \rightarrow \mathrm{Ca}\left(\mathrm{NO}_{3}\right)_{2}+2 \mathrm{H}_{2} \mathrm{O}---
$$

The decomposition of the primary hydration products can lead to increased porosity and permeability, with loss of strength and adhesion. Acids can also deteriorate limestone aggregates.

In addition, nitrates and nitrites can take part in the formation of various salts that can eventually cause the cracking and spalling of cementitious materials. These ions can possibly combine with calcium ions $(\mathrm{Ca}+)$ that are readily abundant in cement-based materials, forming various nitrogenous compounds of calcium (e.g., $\mathrm{Ca}\left(\mathrm{NO}_{2}\right)_{2}$, $\left.\mathrm{Ca}\left(\mathrm{NO}_{3}\right)_{2}\right)$. These salts are readily soluble in water, meaning that they can participate in repeated dissolution and recrystallization cycles. Salt crystallization damage to porous materials, including cement-based materials, has been reported numerous times in the literature. Crystallization of sodium chloride $(\mathrm{NaCl})[12,13,14]$, sodium carbonate $\left(\mathrm{Na}_{2} \mathrm{CO}_{3}\right)$ [13], sodium thiosulfate pentahydrate $\left(\mathrm{Na}_{2} \mathrm{~S}_{2} \mathrm{O}_{3}-5 \mathrm{H}_{2} \mathrm{O}\right)[15]$, and sodium sulfate $\left(\mathrm{Na}_{2} \mathrm{SO}_{4}\right)[16,17]$ are known to cause the cracking of porous materials, including cement-based materials, due to salt crystallization pressure. It is possible that $\mathrm{Ca}\left(\mathrm{NO}_{2}\right)_{2}$ or $\mathrm{Ca}\left(\mathrm{NO}_{3}\right)_{2}$ salts resulting from photocatalysis take part in disruptive salt crystallization damage on cementitious materials.

Lastly, cementitious materials undergo carbonation when exposed to atmospheric carbon dioxide $\left(\mathrm{CO}_{2}\right)$ and moisture. Upon carbonation, the chemical composition of the surface of a material is altered which is accompanied by changes in the porosity and inner structure of cement-based materials, along with changes in photocatalytic efficiency. Lackhoff et al. examined the influence of carbonation on the degradation rate of atrazine, and found a reduction of photocatalytic activity that was possibly due to 
decreased specific surface area, decreased atrazine sorptivity, and calcite overgrowth on the cement surface[18]. Chen et al. performed experiments on NOx degradation, where they also found reduced photocatalytic efficiency after surface carbonation, possibly due to $\mathrm{CaCO}_{3}$ deposition in pores, thus reducing total porosity[19].

The objectives of this study were to examine whether the oxidation of NOx during the photocatalysis could influence the durability of cementitious substrate, and to investigate the oxidation efficiency of NOx in the long term. To this end, $\mathrm{TiO}_{2}-$ containing cement pastes were exposed to environmental conditions meant to simulate and also accelerate environmental exposures that could possibly lead to degradation of this material, through acid attack and salt crystallization. Both $\mathrm{NO}$ and $\mathrm{NO}_{2}$ gases were utilized for this study, and samples were exposed to cycles of NOx and UV (i.e., surface photocatalysis) along with wetting and drying conditions. To quantify the influence of these surface reactions on the cement substrate, the surface of each set of samples was examined by scanning electron microscopy (SEM), Vickers microhardness test, and $\mathrm{X}$-ray diffraction analysis. In addition, photocatalytic efficiency was monitored throughout the experiment.

The study was conducted in two parts; the first part utilized nitric oxide (NO) gas to examine the photocatalytic efficiency and durability of photocatalytic cement. The second part utilized nitrogen dioxide $\left(\mathrm{NO}_{2}\right)$ gas with an accelerated testing procedure. This paper reports only the first part, in which $\mathrm{NO}$ was used.

\section{Experiment}

The overall experiment followed a process shown in Figure 1. Once the samples were prepared, which will be explained in more detail in section 2.1, surfaces of test samples were examined prior to the exposure to NO and UV in order to establish a base measure- ment. Then, the samples were subjected to multiple cycles of environmental exposures, termed as "cycling" in this paper. One cycle starts with exposure to NO test gas and UV light for the photocatalytic reaction, followed by wetting and drying, and then the next cycle starts again by exposure to NO and UV. This process of cycling was designed to simulate the actual environmental situation in which photocatalytic materials go through various weathering conditions, such as rain/dew and dry weather, which could possibly affect the long-term durability of the cementitious substrate, as stated in the introduction. During the course of these cyclings, sample surfaces were examined after the drying step of every 5 cycles respectively, in order to capture any gradual changes in their physical, mechanical, and chemical properties. Specific details on the methodology of the cycling and surface examination are discussed in sections 2.2 and 2.3, respectively.

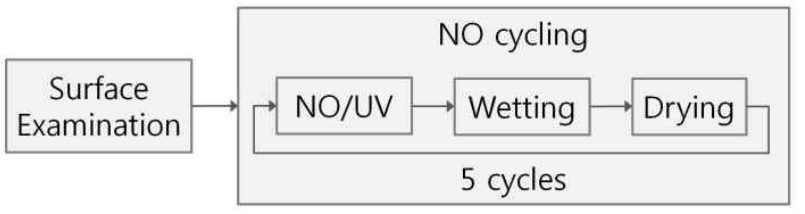

Figure 1. Diagram of the experimental process

As described in the introduction, nitric oxide (NO) was selected as the test gas for the experiment, as described in most of the standard testing[20,21].

\subsection{Materials and Sample Preparation}

Cement paste samples containing nano- $-\mathrm{TiO}_{2}$ particles were prepared. The $\mathrm{TiO}_{2}$ powder utilized was P25 (Aeroxide $\mathrm{TiO}_{2}$ P25, Evonik Industries). The $\mathrm{TiO}_{2}$ powder consisted of $80 \%$ anatase and $20 \%$ rutile, with an average crystal size of $21 \mathrm{~nm}$. The surface area 
is $50 \pm 15 \mathrm{~m}^{2} / \mathrm{g}$, and the sample purity is $99.5 \%$, as stated by the manufacturer. The cement used was ASTM C 150 Type I Portland cement, the Bogue potential composition of which was $51.30 \% \mathrm{C}_{3} \mathrm{~S}$, $19.73 \% \mathrm{C}_{2} \mathrm{~S}, 8.01 \mathrm{C}_{3} \mathrm{~A}$, and $9.41 \% \mathrm{C}_{4} \mathrm{AF}$. (The cement chemistry notations of these oxides are defined as $\mathrm{C}=\mathrm{CaO}, \mathrm{S}=\mathrm{SiO}_{2}, \mathrm{~F}=\mathrm{Fe}_{2} \mathrm{O}_{3}$, and $\mathrm{A}=\mathrm{Al}_{2} \mathrm{O}_{3}$.)

The samples were prepared at w/c of 0.50 at $5 \%$ $\mathrm{TiO}_{2}$ replacement by mass of cement. When mixing, $\mathrm{TiO}_{2}$ particles were pre-mixed with deionized water for 1 minute using a hand-held mixer at a low speed. Cement was then added to the $\mathrm{TiO}_{2}$ slurry and mixed for 1 additional minute at a low speed and another 1 minute at a medium speed. Samples were cast in plastic molds with dimensions of $4.8 \mathrm{~cm} \times 4.8 \mathrm{~cm} \times$ $0.8 \mathrm{~cm}$. They were allowed to cure in a $100 \%$ relative humidity environment at $23 \pm 2^{\circ} \mathrm{C}$ for the initial 24 hrs, and continued to be cured in limewater after demolding at $23 \pm 2^{\circ} \mathrm{C}$. The samples were taken out of the limewater at 14 days of age, polished to $0.3 \mu \mathrm{m}$, and dried in the oven at $30^{\circ} \mathrm{C}$ for 3 full days. The samples were polished to better identify microhardness marks. The dried samples were stored in air-tight plastic bags until they were tested.

The NO gas was obtained in a cylinder at $100 \mathrm{ppm}$. It was mixed with ultra-pure zero air ( $~ 80 \%$ nitrogen and $\sim 20 \%$ oxygen) to a target value of $1200 \mathrm{ppb}$ at the output of the UV reactor when the samples are installed. Mass flow controller was used constantly for both the NO and the zero air to maintain the desired concentration.

\subsection{Experimental Procedure}

The general procedure for the cycling was already introduced in Figure 1. In this section, specific details of each of the steps, the NO-UV experiment, wetting, and drying, are introduced.

Each cycle starts with the NO-UV experiment. This step uses a UV reactor that was designed to largely conform to the ISO and JIS standards[20,21] for measurements of removal of nitric oxide during photocatalysis. The inner width of the reactor was increased from $5 \mathrm{~cm}$ to $8 \mathrm{~cm}$ to accommodate larger samples. Figure 2 is a schematic of the NO-UV experiment, with the UV reactor shown in the center. The test set-up was designed to maintain a constant concentration of test gas flow into the reactor, which then flows over the sample surfaces (which may be illuminated with UV light), and exits on the other side of the chamber where gas concentration is measured with time. Samples were placed in the reactor with only one face exposed to the UV light and the test gas. Two 40W UV fluorescent lamps with peak emission at $368 \mathrm{~nm}$ were used to produce the UV light. The power density of the UV light at the sample surface was maintained at $10 \mathrm{~W} / \mathrm{m}^{2}$ by adjusting the distance between the light source and the sample plane.

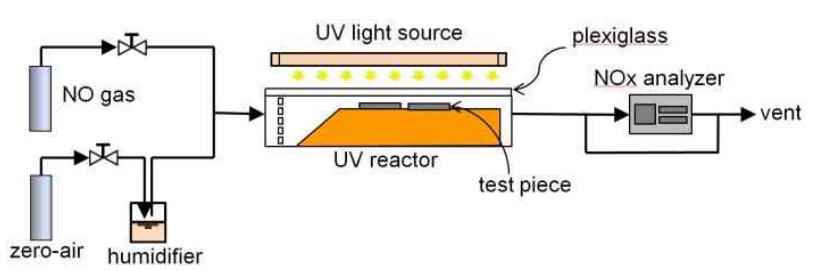

Figure 2. Schematic of NO-UV

Before and between each cycle, the samples were stored in air-tight plastic bags in a dry condition. After the installation of the samples in the chamber, a constant concentration of NO was injected until the gas concentration was stabilized, which required at least one hour. Gas flow rate was constant at 1000 $\mathrm{ml} / \mathrm{min}$. During the gas stabilization time, the UV light was turned on for 15 minutes with the shutter closed to warm it up. Once the gas was stabilized, the shutter was opened and the samples were exposed to the UV irradiation, leading to the onset of the photocatalytic reaction. The NO-UV exposure time was 5 hours for all the cycles. After the designated 
time of UV exposure, the UV light was turned off and the gas concentration was kept recorded until the concentration is stabilized again, which took about one hour. Then, the gas supply was stopped and the samples were collected and transported in an air-tight container for wetting. The humidity of the test gas was maintained at 50\% $\mathrm{RH}$. The photocatalytic oxidation efficiency was determined twice for each run; it was first measured by the drop of NOx concentration when the UV light was turned on, and was measured the second time based on the amount of NOx concentration recovery when the UV light was turned off. The results were normalized by the number of tiles, where the individual tile surface area was kept constant at $\sim 23 \mathrm{~cm}^{2}$.

After the NO-UV exposure, samples were subjected to a wetting and drying process to simulate rain/dew and dry conditions that could contribute to the deterioration of these cementitious materials. For each sample, $0.75 \mathrm{~g}$ of deionized water was uniformly spread on the top surface of a sample, which corresponds to a water layer of $0.3 \mathrm{~mm}$, simulating dew or light rain. Only the top surfaces of the specimen were wetted where the photocatalytic reaction takes place. The samples were then stored in a $100 \% \mathrm{RH}$ container for 4 hours. During this time, the water and products of $\mathrm{NO}$ oxidation could penetrate into cementitious materials, which could possibly contribute to deterioration. Following the wetting, samples were dried in an oven at $40^{\circ} \mathrm{C}$. The drying time was 15 hours. After the drying step, sample mass was measured and the next cycle was performed by exposing samples to the NO-UV. This cycling was repeated for 20 cycles.

\subsection{Surface Examinations}

Before and between cycling, sample surfaces were examined. The surface examination was performed once every 5 cycles. Sample surfaces were examined through three different techniques: scanning electron microscopy, Vickers microhardness test, and $\mathrm{X}$-ray diffraction analysis.

Scanning electron microscopy (SEM) was used to visualize and compare the surface morphology before and after the NO-wet-dry cycling. This method is suitable for microcharacterization of the sample's surface because of its high magnification. For the SEM, a sample was carefully broken into small pieces and conditioned in an oven at $30^{\circ} \mathrm{C}$ for three days before the analysis. Samples were neither surface-treated nor coated in an effort to preserve and capture the surface after possible changes.

Microhardness of the sample surfaces was examined using Vickers indenter as per the ASTM C 1327 standard[22] in order to evaluate any changes in the mechanical properties of the sample surfaces after repeated exposure to the NO-UV and wet-drying. This technique is suitable for investigating microstructural mechanical properties on the surface of a material, and has been used in several earlier studies on cement pastes, mortars, and concretes[23,24,25,26]. Three samples were pre-selected for this purpose throughout the experiment, and ten indentations were made per sample before and between 5 cycles at locations free from any visible surface defects, for consistency. Loading cell used was 1000gf. Vickers hardness numbers for the 30 indentations were averaged and standard deviations were calculated.

$\mathrm{X}$-ray diffraction analysis was performed to qualitatively assess any chemical changes that might have occurred during the photocatalytic oxidation and wet-drying cycling near the surface of samples. Surface of a sample was scraped to $\sim 1 \mathrm{~mm}$ depth with a razor blade. The powder was then ground with mortar and pestle and analyzed under $\mathrm{Cu}-\mathrm{K}$ radiation for 12.5 hours at $2 \theta$. from $5^{\circ}$ to $65^{\circ}$. Diffraction patterns were normalized by the peak of $\mathrm{TiO}_{2}$ at $2 \theta=25.43$ for accurate comparison. 


\section{Results and Discussion}

\subsection{Photocatalytic Efficiency}

Photocatalytic efficiency was determined at each NO-UV cycle. In each experiment, a sharp drop in the gas concentration was observed when the UV light was turned on, and the quick recovery of the gas concentration level was observed when the UV light was turned off. This is a well-known behavior of a photocatalytic reaction, such as on the surface of cement. Of the NOx concentration plots from each cycle, the plot for the first cycle is presented in Figures 3. The number of samples used for the experiment was 6 , and thus the results presented should be normalized by the exposed surface area of samples to get the photocatalytic efficiency. Note that the concentration of the $\mathrm{NO}_{2}$ is plotted as well, so as to show the amount of gas conversion between $\mathrm{NO}$ and $\mathrm{NO}_{2}$ during the test, if any.

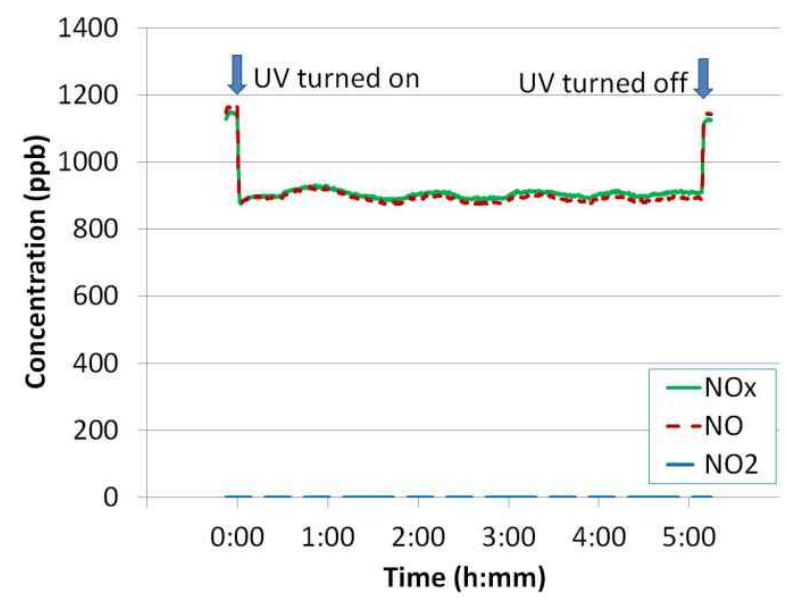

Figure 3. $\mathrm{NOx}, \mathrm{NO}$ and $\mathrm{NO}_{2}$ concentration at 1 st cycle

Both the initial drop in NOx concentration when the UV light is turned on and the final increase in NOx concentration when the UV light is turned off were measured. The results were divided by the number of tiles to facilitate comparison. The photocatalytic efficiency per sample was calculated for each cycle and the results of which are shown in Figure 4. It was observed that the maximum NOx binding rate occurred in the 4 th -6 th cycles at $\sim 55 \mathrm{ppb}$, and reduced to $\sim 25 \mathrm{ppb}$ at the 20 th cycle. Throughout the experiment, the amounts of initial NOx drop and final NOx increase for each cycle were similar, indicating that the NOx binding rate was relatively steady throughout each NO-UV exposure. The differences between the initial and final NOx concentration in each cycle varies up to $10 \mathrm{ppb}$, which could be explained as an experimental error, such as due to sample storing condition, minor temperature changes, and NOx stabilization level. Interestingly, it was observed that the NO oxidation rate decreased as the number of cycles increased. That is, the repeated NO exposure and wet-dry cycling had a negative effect on the photocatalytic oxidation. Considering that the $\mathrm{TiO}_{2}$ particles are responsible for the reaction and they do not change during chemical reactions, this suggests that the sample surface has been modified due to photocatalytic NO oxidation. Possible explanations are discussed later in this chapter.

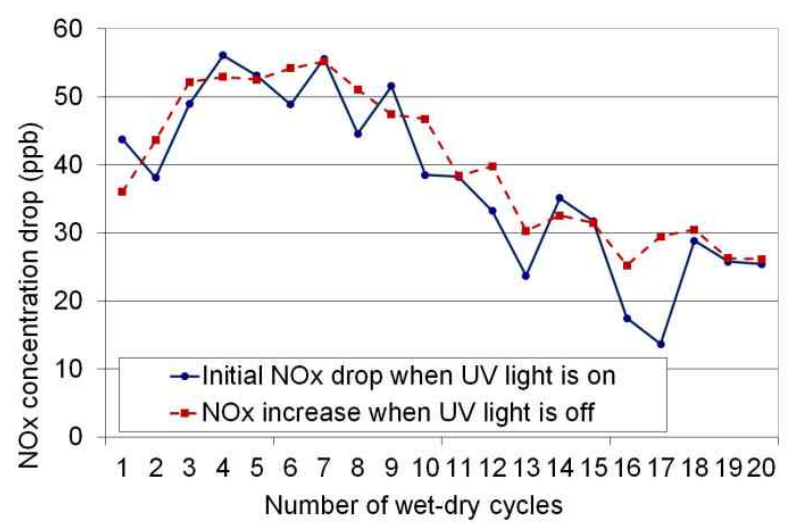

Figure 4. NOx concentration changes per tile when UV light is on/off

\subsection{Scanning Electron Microscopy}

Scanning electron microscopy was used to closely examine the surface of a sample exposed to NO-UV and wet-dry cycling. Figure 5 presents SEM images of samples under $\mathrm{NO}$ gas at 0 and 20th cycle. It was 
observed that pits less than $1 \mu \mathrm{m}$ were created on the sample surface with exposure to NO-wet-dry cycling. This suggests that there has been either chemical deterioration by acid attack or leaching, or the $\mathrm{TiO}_{2}$ particles could have been lost due to the deterioration. $\mathrm{TiO}_{2}$ particles might have popped out of the surface due to the loss of bonding or because of the oxidation products accumulating on the surface of the $\mathrm{TiO}_{2}$ particles, and could possibly have been lost. This can be related to the lower photocatalytic efficiency with continued cycling, as shown in Figure 4. It is expected that further cycling will create more of these pits and develop current pits deeper and wider. Overall, the results suggest that NO-UV exposure and wet-dry cycling do affect cementitious materials by deteriorating surfaces. Further research is needed to examine how the damage may progress with a longer duration of exposure.

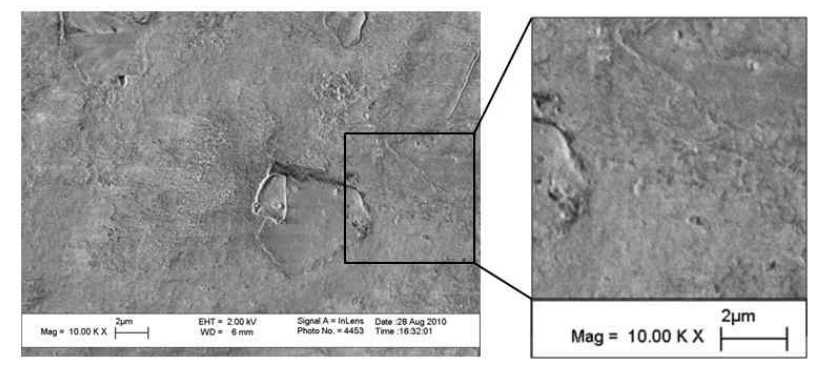

(a)

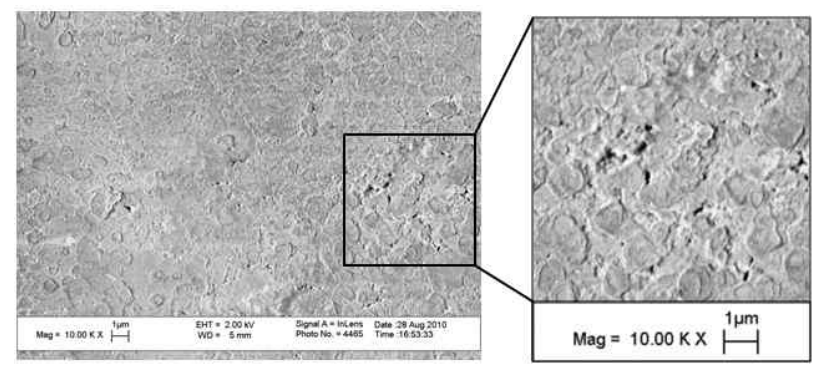

(b)

Figure 5. SEM image of a sample in NO experiment (a) before exposure, (b) after 20 cycles of exposure

\subsection{Microhardness}

Surface microhardness was measured using the Vickers indentation method on samples periodically after every 5 cycles. As shown in Figure 6, at 0 cycles when the samples were not exposed to any environmental conditions, the microhardness was measured as 45. With UV and wet-drying cycling, the samples experienced a $40 \%$ increase in hardness. This could most likely be explained by the continued hydration of the cement. The samples were cured for just 14 days when the experiment started, and as a result, the wetting process could have promoted further cement hydration, and thus the hardness might have increased. This is shown in greater detail in the X-ray diffraction results section, where the amounts of $\mathrm{C}_{3} \mathrm{~S}$ and $\mathrm{C}_{2} \mathrm{~S}$ decreased after cycling. Another possible explanation is an increased amount of calcium carbonate, as evidenced in the X-ray diffraction analysis.

Overall, no clear sign of a decrease in hardness was observed. Thus, it is suggested that the effects of acid attack and salt crystallization, if any, do not have a noticeable effect on the microhardness of cementitious materials.

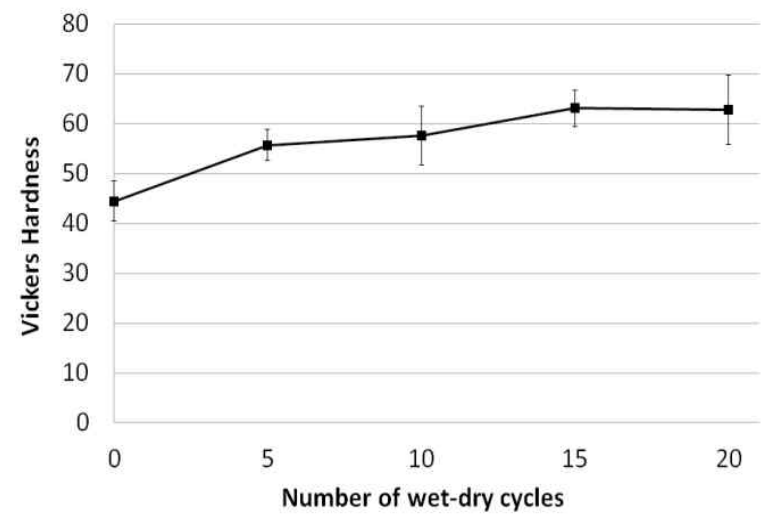

Figure 6. Vickers hardness of samples

\subsection{X-ray Diffraction Analysis}

After every 5 cycles of the experiments, $\sim 1 \mathrm{~mm}$ of surface material was obtained from the sample and analyzed using X-ray diffraction. Diffraction patterns were normalized by maximum peak of the anatase, because it is chemically inert and constant 
among samples of each type. The diffraction patterns are shown in Figure 7.

Interestingly, neither $\mathrm{Ca}\left(\mathrm{NO}_{3}\right)_{2}$ nor $\mathrm{Ca}\left(\mathrm{NO}_{2}\right)_{2}$ salts of various forms of hydrates were detected using this technique. This could be understood by considering several circumstances. The amount of salts produced might be too little to be detected by this technique, or the salts might have transported into deeper pore structure during multiple wet-dry cycling. Other explanations could be that the nitrates and nitrites might have formed other types of salts or chemically bound in cement. Recently, Balonis et al. suggested that cement has the capability to bind nitrates and nitrites by substituting hydroxide, sulfate and carbonate from the AFm structures, forming "nitrate AFm" and "nitrite AFm"[27]. Chung et al. also noted the possibility that nitrate-based AFm could be developed depending on the concentration of nitrate ions within the pore solution[28]. However, the main peaks of nitrate $\mathrm{AFm}$ at $2 \theta=8.41^{\circ}-10.20^{\circ}$ and nitrite $\mathrm{AFm}$ at $2 \theta=11.04^{\circ}-11.23^{\circ}$, as suggested by Balonis et al., were not found by this technique. It should be noted that the X-ray diffraction analysis is not capable of detecting substances that are less than $5 \%$ of the sample by volume.

It is observed that peaks of calcium carbonate $\left(\mathrm{CaCO}_{3}\right.$, designated with $\left.\star\right)$ increased as the number of wet-dry cycles increased. This is an indication of carbonation, which occurs to cementitious materials when exposed to atmospheric carbon dioxide $\left(\mathrm{CO}_{2}\right)$ and moisture, as previously stated in the introduction. The carbonation alters the chemical composition of the paste, which in turn may affect its porosity and microstructure. These changes can affect photocatalytic reactivity, since carbonation also occurs on surface of a material. It has been experimentally determined that cement carbonation decreases the rate of photocatalytic oxidation[18,19]. Lackhoff et al. examined the influence of carbonation on the degradation rate of atrazine, one of the organic compounds, and found a reduction of photocatalytic activity that was possibly due to decreased specific surface area, decreased atrazine sorptivity, and calcite overgrowth on the cement surface[18]. Chen et al. also found reduced photocatalytic efficiency of NOx degradation after surface carbonation, possibly due to $\mathrm{CaCO}_{3}$ deposition in pores that caused a reduction in total porosity[19]. It may also be the case in these experiments that the increased $\mathrm{CaCO}_{3}$ affected the photocatalytic efficiency. The calcite could have filled the pores near the surface, perhaps contributing to increased hardness in the NO-exposed samples. The calcite growth might have covered the $\mathrm{TiO}_{2}$ nanoparticles, hindering the photocatalytic oxidation reaction.

On the other hand, a decreased amount of $\mathrm{C}_{3} \mathrm{~S}$ and $\mathrm{C}_{2} \mathrm{~S}$ is observed as more cycling was performed. This implies that unhydrated $\mathrm{C}_{3} \mathrm{~S}$ and $\mathrm{C}_{2} \mathrm{~S}$ further hydrated during the wet-dry cycling, producing $\mathrm{C}-\mathrm{S}-\mathrm{H}$. Although amorphous $\mathrm{C}-\mathrm{S}-\mathrm{H}$ cannot be detected using the $\mathrm{X}$-ray diffraction technique, it is the primary strength-giving phase, which supports the microhardness data where the sample hardness was increased as more cycling was performed.

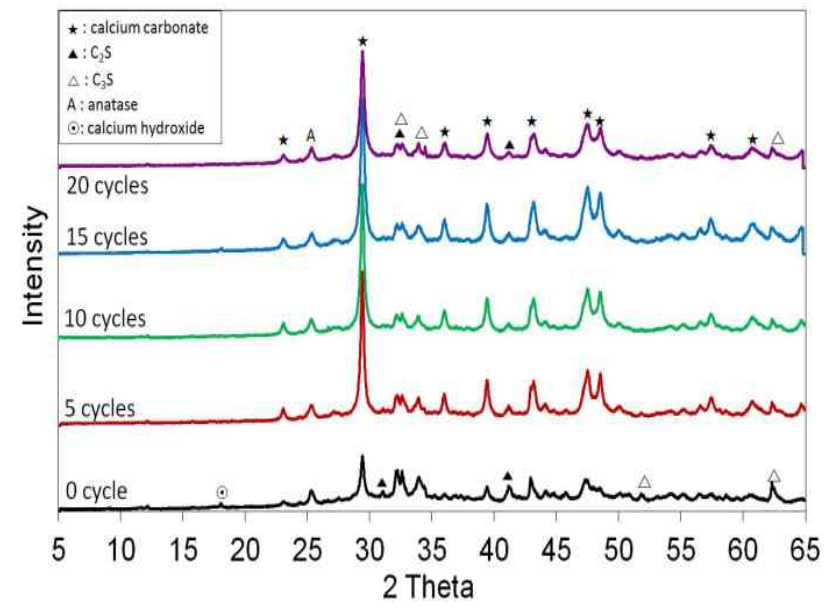

Figure 7. X-ray diffraction pattern of samples exposed to NO wet-dry cycling

$\left(\star\right.$ : calcium carbonate, $\odot$ : calcium hydroxide, $\boldsymbol{\Delta}: \mathrm{C}_{2} \mathrm{~S}, \triangle \mathrm{C}_{3} \mathrm{~S}$, A: anatase ) 


\section{Conclusions}

The durability and efficiency of photocatalytic cement, which might have gone through acid attack, salt crystallization, leaching, and carbonation by exposure to cycles of NO-UV and wet-dry conditions, was experimentally investigated. Based on the results of this study, the following conclusions are drawn:

- Nitric oxide gas was efficiently oxidized by the UV irradiation in the early exposure. However, with continued exposure to NO-UV and wet-dry cycling, the rate of photocatalytic oxidation decreased. This is thought to be a result of the carbonation and continued hydration of $\mathrm{C}_{3} \mathrm{~S}$ and $\mathrm{C}_{2} \mathrm{~S}$. It is believed that calcium carbonate and hydrated cement phases cover the $\mathrm{TiO}_{2}$ particles in cement paste samples, thus hindering the photocatalytic reactions.

- The SEM results demonstrate that the sample surfaces were chemically deteriorated, as evidenced by pits found from the sample surfaces. The pits could possibly indicate that there was acid attack or leaching during the repeated NO-wet-dry cycling. It also suggests that the environmental condition used for this study could initiate the degradation of cementitious materials, and could further affect long-term durability.

- The microhardness values increased with the cycling, indicating that the NO-wet-dry cycling did not decrease the hardness property of cement pastes. Rather, the hardness of the samples increased, possibly due to continued hydration of cement and carbonation. The possible acid attack, as found from the SEM, and the salt crystallization, could not be found by this technique.
- The X-ray diffraction patterns indicate that the formation of calcium carbonate was the most pronounced. The amount of unhydrated $\mathrm{C}_{3} \mathrm{~S}$ and $\mathrm{C}_{2} \mathrm{~S}$ were decreased after cycling, meaning that they were hydrated during the cycling. These results support results from microhardness. Any possible nitrate and nitrite salts were not detected using XRD, possibly because the amount produced was very little, or those produced might have transported to the inner pore structure.

\section{References}

1. Husken G., Hunger M., Brouwers H.J.H. Experimental study of photocatalytic concrete products for air purification. Building and Environment. 2009 Dec; 44(12): 2463-74.

2. Poon C.S., Cheung E. NO removal efficiency of photocatalytic paving blocks prepared with recycled materials. Construction and Building Materials. 2007 Aug; 21(8): 1746-53.

3. Husken G., Hunger M., Brouwers H. Comparative study on cementitious products containing titanium dioxide as photo-catalyst. In: Baglioni P, Cassar L, editors. International RILEM Symposium on Photocatalysis, Environment and Construction Materials; 2007 Oct 8-9; Firenze, Italy. Bagneux: RILEM Publications SARL; 2007. p. 147-54.

4. Beeldens A. Air purification by road materials: Results of the test project in Antwerp. In: Baglioni P, Cassar L, editors. International RLEM Symposium on Photocatalysis, Environment and Construction Materials; 2007 Oct 8-9; Firenze, Italy. Bagneux: RILEM Publications SARL; 2007. p. 187-94.

5. Maggos T., Plassais A., Bartzis J.G., Vasilakos C., Moussiopoulos N., Bonafous L. Photocatalytic degradation of NOx in a pilot street canyon configuration using $\mathrm{TiO}_{2}-$ mortar panels. Environmental Monitoring and Assessment. 2008 Jan; 136(1-3): $35-44$.

6. Devahasdin S., Fan C., Li K.Y., Chen D.H. TiO2 photocatalytic oxidation of nitric oxide: transient behavior and reaction kinetics. Journal of Photochemistry and Photobiology a-Chemistry. 2003 Mar; 156(1-3): 161-70.

7. Laufs S., Burgeth G., Duttlinger W., Kurtenbach R., Maban M. Thomas C., Wiesen P., Kleffmann J. Conversion of nitrogen oxides on commercial photocatalytic dispersion paints. Atmospheric Environment. 2010 Jun; 44(19): 2341-9.

8. Ohko Y., Nakamura Y., Fukuda A., Matsuzawa S., Takeuchi 
K. Photocatalytic oxidation of nitrogen dioxide with $\mathrm{TiO}_{2}$ thin films under continuous UV-light illumination. Journal of Physical Chemistry C. 2008 Jun; 112(28): 10502-8.

9. Tseng Y.H., Kuo C.S., Huang C.H., Li Y.Y., Chou P.W., Cheng C.L., Wong M.S. Visible-light-responsive nano- $\mathrm{TiO}_{2}$ with mixed crystal lattice and its photocatalytic activity. Nanotechnology. 2006 May; 17(10): 2490-7.

10. Beaumont S.K., Gustaftson R.J., Lambert R.M. Heterogeneous Photochemistry Relevant to the Troposphere: $\mathrm{H}_{2} \mathrm{O}_{2}$ Production during the Photochemical Reduction of $\mathrm{NO}_{2}$ to $\mathrm{HONO}$ on UV-Illuminated $\mathrm{TiO}_{2}$ Surfaces. Chemphyschem. 2009 Feb; 10(2): 331-3.

11. Ndour M., D'Anna B., George C., Ka O., Balkanski Y., Kleffmann J., Stemmler K., Ammann M. Photoenhanced uptake of $\mathrm{NO}_{2}$ on mineral dust: Laboratory experiments and model simulations. Geophysical Research Letters. 2008 Mar; 35(5).

12. Idorn G.M. Concrete progress : from antiquity to third millennium. London: Thomas Telford; 1997. 359 p.

13. Haynes H., O'Neill R., Neff M., Mehta P.K. Salt weathering of concrete by sodium carbonate and sodium chloride. ACI Materials Journal. 2010 May; 107(3): 258-66.

14. Lewin S.Z., The mechanism of masonry decay through crystallization. in Conservation of historic stone buildings and monuments. Washington, D.C.: The National Academy Press; 1982. 120-44.

15. Chatterji S., Thaulow N. Unambiguous demonstration of destructive crystal growth pressure. Cement and Concrete Research. 1997 Jun; 27(6): 811-6.

16. Scherer G.W. Stress from crystallization of salt. Cement and Concrete Research. 2004 Sep; 34(9): 1613-24.

17. Thaulow N., Sahu S. Mechanism of concrete deterioration due to salt crystallization. Materials Characterization. 2004 Nov; 53(2-4): 123-7.

18. Lackhoff M., Prieto X., Nestle N., Dehn F., Niessner R. Photocatalytic activity of semiconductor-modified cement influence of semiconductor type and cement ageing. Applied Catalysis B-Environmental. 2003 Jul; 43(3): 205-16.

19. Chen J., Poon C.S. Photocatalytic cementitious materials: Influence of the microstructure of cement paste on photocatalytic pollution degradation. Environmental Science \& Technology. 2009 Nov; 43(23): 8948-52.

20. ISO, Fine ceramics (advanced ceramics, advanced technical ceramics) - Test method for air-purification performance of semiconducting photocatalytic materials, in Part 1: Removal of nitric oxide. 2007.
21. JIS, Fine ceramics (advanced ceramics, advanced technical ceramics) - Test method for air purification performance of photocatalytic materials in Part 1: Removal of nitric oxide. 2004.

22. ASTM, ASTM C 1327 Standard test method for Vickers indentation hardness of advanced ceramics. 2008.

23. Igarashi S., Bentur A., Mindess S. Microhardness testing of cementitious materials. Advanced Cement Based Materials. 1996 Sep; 4(2): 48-57.

24. Trtik P., Bartos P.J.M. Micromechanical properties of cementitious composites. Materials and Structures. 1999 Jun; 32(219): 388-93.

25. Cross W.M., Sabnis K.H., Kjerengtroen L., Kellar J.J. Microhardness testing of fiber-reinforced cement paste. ACI Materials Journal. 2000 Mar; 97(2): 162-7.

26. Hossain K.M.A. Macro- and microstructural investigations on strength and durability of pumice concrete at high temperature. Journal of Materials in Civil Engineering. 2006 Aug; 18(4): $527-36$.

27. Balonis M., Medala M., Glasser F.P. Influence of calcium nitrate and nitrite on the constitution of AFm and AFt cement hydrates. Advances in Cement Research. 2011 Jun; 23(3): 129-143.

28. Chung C.W., Urn W., Valenta M.M., Sundaram S.K., Chun J., Parker K.E., Kimura M.L., Westsik J.H. Characteristics of Cast Stone cementitious waste form for immobilization of secondary wastes from vitrification process. Journal of Nuclear Materials. 2012 Jan; 420(1-3): 164-74. 